\title{
VARIÁVEIS DESCRITIVAS DO ESTILO DE ILUSTRAÇÃO EM SEQUÊNCIA PICTÓRICA DE PROCEDIMENTOS PARA BULAS DE MEDICAMENTOS
}

\section{DESCRIPTIVE VARIABLES OF ILLUSTRATION STYLE IN PROCEDURAL PICTORIAL SEQUENCE OF MEDICINE LEAFLETS}

\author{
Luiz Gustavo Amorim Lope ${ }^{\mathrm{s} 1}, \mathrm{Me}$ \\ Carla Galvão Spinillo², $\mathrm{PhD}$ \\ (1) Universidade Federal do Paraná \\ e-mail: gustavo.amorim.1904@gmail.com \\ (2) Universidade Federal do Paraná \\ e-mail:cgspin@gmail.com
}

Estilo de Ilustração, Bula de Medicamentos, Sequência Pictórica de Procedimento

\begin{abstract}
O propósito desse artigo é verificar o estilo de ilustração em instruções visuais, cujo objetivo se delimita em identificar e descrever o estilo de ilustração empregados nas bulas de medicamentos brasileiras. O método utilizado nesse levantamento consiste em uma análise descritiva do estilo das representações presentes em instruções visuais, assim as informações serão levantadas a partir de dois modelos avaliativos Spinillo (2001) e Ashwin (1979), a amostra será compostas pelos documentos disponibilizados no bulário eletrônico, site onde estão cadastradas todas as bulas de medicamentos comercializadas nacionalmente e disponível para acesso gratuito para toda a população. De tal modo o presente artigo se divide com os seguintes tópicos: (1) Introdução; (2) Instruções visuais em bulas, (3) Estilo de ilustração, com os principais conceitos e definições; (4) Método, com detalhamento dos modelos empregado para a análise; (5) Resultados obtidos a partir da amostra, assim como os detalhes e características dos dados coletados durante o experimento, (6) Considerações finais verificadas nos estilos de ilustração, a utilização do texto como complementação da imagem procedimental, normatização dos elementos de ênfase e simbólicos, além da regularização das ilustrações procedimentais pelos órgãos competentes.
\end{abstract}

\section{Illustration Style, Medication Leaflet, Procedural Pictorial Sequence}

The purpose of this paper is to evaluate the instructional style in medicinal package inserts. The purpose concerns the identification and description of the illustration styles used in leaflets produced in Brazil. The method used in this survey consists of a descriptive analysis the style of the representations present in visual instructions, based in information obtained from two evaluation models - Spinillo (2001) and Ashwin (1979). The sample will be composed by documents available in the electronic leaflets index, a website in which all the medicines leaflets are marketed nationally and available for free access for the entire population. Therefore, the present article divides in the following topics: (1) Introduction; (2) Visual instructions of medicinal leaflets; (3) Illustration style, its main concepts and definitions; (4) Method, with details of the models used for the analysis; (5) Results obtained from the sample, as well as details and characteristics of the data collected during the experiment; (6) Considerations in the styles of illustration, the use of text as a complement to the procedural image, normalization of the elements of emphasis and symbolic, furthermore the regularization of procedural illustrations by the competent bodies. 


\section{$16^{\circ}$ \\ ERGODESIGN USIHC CINAHPA}

\section{Introdução}

A saúde é uma área de extrema importância de caráter mundial, no Brasil esses direitos são regidos pela sua própria Constituição Federal de 1988, conforme cita o artigo 196, que "A saúde é um direito de todos e um dever do estado", assim como no artigo 197, que estabelece as competências do Poder publico aos serviços de saúde por meio da sua "regulamentação, fiscalização e controle” (BRASIL, 2006, p.07).

Observa que a farmacoterapia ${ }^{1}$ é área que apresenta as maiores dificuldades na saúde pública conforme classifica Paracelses (1493-1541) que "todas as substâncias são venenos, não há uma que não seja veneno. A posologia correta diferencia o veneno do remédio", (KLAASSEN, 1985, p. 1047). Nota que a utilização da medicação e o seu tratamento normamente é realizado pelo próprio paciente e todas as informações necessárias para o seu tratamento está disponível apenas na bula, sendo ela como o único documento que acompanha a medicação após a compra. Nota que a bula passa a ser um importante documento de consulta pública, a qual disponibiliza informações específicas como composição modo de preparo e a utilização da medicação (FUJITA, et al, 2008).

No âmbito nacional as bulas de medicamentos são regulamentadas por duas resoluções em que definem os critérios para os laboratórios farmacêuticos desenvolverem esse tipo de documento: Resolução da Diretoria Colegiada (RDC) $n^{\circ} 140$ de 2003 e RDC n ${ }^{\circ} 47$ de 2007. Observa que as duas resoluções não apresentam critérios para o desenvolvimento das ilustrações instrucionais, utilizada para auxiliar na realização da tarefa do prepara e/ou uso da medicação presente nas bulas de medicamentos.

Destaca-se o estado do Paraná, como o pioneiro a estabelecer critérios para essas representações. A resolução SESA (Secretária do Estado da Saúde) nº 62 de 2013, estabelece algumas normativas para as bulas de

\footnotetext{
${ }^{1}$ Aplicação dos medicamentos na prevenção ou tratamento de doenças (ANVISA, 2015).
}

$16^{\circ}$ Ergodesign - Congresso Internacional de Ergonomia e Usabilidade de Interfaces Humano Tecnológica: Produto, Informações Ambientes Construídos e Transporte

$16^{\circ}$ USIHC - Congresso Internacional de Ergonomia e Usabilidade de Interfaces Humano Computador

CINAHPA | 2017 - Congresso Internacional de Ambientes Hipermídia para Aprendizagem.

medicamentos magistrais ${ }^{2}$ com relação à construção do documento como as características textuais (fonte, tamanho e espaçamento) e algumas recomendações para as ilustrações em instruções visuais (PARANÁ, 2013b, p. 8).

As imagens instrucionais, assim como qualquer outra representação visual, têm o seu estilo de composição própria e fator primordial, possuindo diversas variações. Para Gombrich (1995, p. 3) aponta que o estilo é o fator que diferencia uma representação, seja por meio da aplicação de diferentes técnicas seja por características da própria personalidade do ilustrador.

Neste artigo apresentaremos como o estilo de ilustração está presente nas instruções visuais em bulas de medicamentos e como elas estão sendo representadas nesses documentos para a realização dos procedimentos.

\section{Instruções visuais em bulas}

As razões para o uso de ilustrações como instruções visuais são os mais variados, dentre eles: a facilidade de compreensão, a sintetização de conteúdos e a representação de informações pela padronização de ilustração.

Petel (1999) apud Volpato (2010), através de pesquisas realizadas com 40 mães, das quais $55 \%$ possuíam menos de seis anos de escolaridade, pôde avaliar a leitura e compreensão de imagens instrucionais, constatou que após leitura e realização da ação informada (reidratação oral), nas respostas a um questionário individual, as mães tinham recordação das instruções que apresentavam apenas as imagens, não recordando as mensagens textuais das instruções visuais. (PETEL, 1999 apud VOLPATO et al., 2010 p. 312). Verifica que o uso da ilustração em instrução visual é muito variado, e alguns fatores merecem destaque como: apresentação gráfica, textual e pictórica.

\footnotetext{
${ }^{2}$ As abrangências desta resolução são os estabelecimentos farmacêuticos - farmácias que manipulam medicamentos para uso humano (PARANÁ, 2013b, p. 1).
}

Realização:

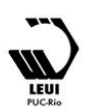




\section{$16^{\circ}$ \\ ERGODESIGN USIHC CINAHPA}

No Brasil os medicamentos são regulamentados pela Agência Nacional de Vigilância Sanitária (ANVISA), com duas resoluções que delimita os critérios para os laboratórios farmacêuticos no desenvolvimento das bulas, a RDC n ${ }^{\circ} 140$ de 2003 e RDC n ${ }^{\circ} 47$ de 2009.

A primeira relaciona as informações contidas em bulas, apresentando a dois tipos de usuários distintos composto por: (1) pacientes e (2) profissionais da saúde. Essa resolução especifica a forma de apresentação do conteúdo do documento, em linguagem acessível, com texto de fácil compreensão e podendo ser formulado por meio de perguntas.

A segunda e mais recente a $\mathrm{RDC} \mathrm{n}^{\circ} 47$ de 2009, define a bula como um documento que possui informações técnico-científicas e orientação do fármaco quanto ao seu uso (RDC 47, 2009, p.

3). Destina às especificações técnicas da bula: diagramação, corpo tipográfico, tamanho da fonte, espaçamento entre letras e textos, largura mínima do suporte, entre outras especificações técnicas que auxiliem os laboratórios no desenvolvimento do material, configurando, dessa maneira, uma padronização (HAMMENSCHMIDT, 2014).

Contudo essas duas resoluções não se aplica para a construção das representações instrucionais em bulas de medicamentos. $\mathrm{O}$ estado do Paraná desenvolveu a resolução SESA n ${ }^{\circ} 62$ de 2013, que estabelece algumas normativas para ás ilustrações destinadas às bulas de medicamentos magistrais, com algumas especificações sendo elas: a forma de representar movimento através do uso de setas, evitar o excesso de detalhes na representação dificultando seu entendimento e devem ser constituídas com fundo neutro (PARANÁ, 2013b, p. 08). Observa que essa normativa apenas se destina aos medicamentos magistrais, não se aplicando essa regulamentação ao âmbito nacional para as demais bulas que são comercializadas no Brasil.

Atualmente o Bulário Eletrônico, base de dados para as bulas de medicamentos, desenvolvidos pela ANVISA, assim apenas em $16^{\circ}$ Ergodesign - Congresso Internacional de Ergonomia e Usabilidade de Interfaces Humano Tecnológica: Produto, Informações Ambientes Construídos e Transporte

$16^{\circ}$ USIHC - Congresso Internacional de Ergonomia e Usabilidade de Interfaces Humano Computador

CINAHPA | 2017 - Congresso Internacional de Ambientes Hipermídia para Aprendizagem.

2014 é que foram cadastradas todas as bulas no sistema online. (ANVISA, 2016 a). Assim, o Bulário Eletrônico, é uma ferramenta que permite a consulta das bases de dados das bulas de medicamentos por todos, podendo ser acesso tanto por profissionais de saúde como os usuários/pacientes da medicação (ANVISA, 2016 b). A busca pelas bulas digitais ocorre através do nome do medicamento ou laboratório/empresa em sua procura inicial, assim o sistema disponibiliza a bula em dois formatos distintos, a Bula do Paciente e a Bula do Profissional de Saúde estão com a presença de termos técnicos no documento, contudo ambos tem acesso os dois formatos de bulas em que é possível realizar a sua leitora no formato digital, ou o se preferir realizar o download para impressão para uma leitura semelhante as bulas encontrada no interior da embalagem do fármaco.

Atualmente os próprios laboratórios farmacêuticos, são os responsáveis pelo desenvolvimento das imagens instrucionais, baseados em seus próprios critérios, sem prévia análise da compreensão do conteúdo da bula e das instruções visuais produzidas junto aos usuários/pacientes através da realização de testes. De modo a não ser realizado um procedimento para verificar o nível de entendimento da representação, acarretando ambiguidade ou incompreensão das imagens instrucionais, o que dificulta na realização da ação proposta pelas sequências instrucionais (SPINILLO et al., 2011).

\subsection{Arte sequêncial em histórias em quadrinhos}

O termo arte sequêncial é abordado por Eisner (1989) e McCloud (1995), para a definição em histórias em quadrinhos. Eisner (1989, p. 05) classifica o termo como a maneira de representação artística e literária a "disposição de figuras ou imagens e palavras para narrar uma história ou dramatizar uma ideia".

Expor uma imagem isoladamente não constitui uma sequência, mas ao acrescentar imagens pode transformar se em uma sequência. McCLoud (1995), descreve os quadrinhos como uma técnica que não possui relação com o objeto
Realização:

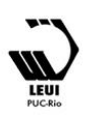




\section{$16^{\circ}$ \\ ERGODESIGN USIHC CINAHPA}

(e.g. gibi ou revista), classificando a arte sequêncial como:

Imagens pictóricas e outras justapostas em sequência deliberada destinadas a transmitir informações e/ou a produzir uma resposta ao espectador (MCCLOUD, 1995 p. 4-9).

Entende-se com as definições de Eisner (1989) e McCloud (1995), qualquer tipo de representação pictórica somente com imagem, textos ou com ambos cujo objetivo é transmitir um conteúdo informacional, com a sequência (imagens) para a construção de uma história com dialogo/narração por meio de textos/palavras.

Os quadrinhos são uma forma de arte principalmente visual, sua arte chame a atenção do leitor, fazendo com que o artista aplique suas habilidades na representação através do estilo, técnicas e recursos gráficos para que alcance tais objetivos (EISNER, 1989, p. 123).

Eisner (1989, p. 124-125) apresenta a relação que existe entre texto e arte enfraquecendo ou enfatizando uma característica através dos artistas ou escritores das histórias em quadrinhos. Com relação a sua forma ou estilo de representação faz com que o leitor demonstre diferentes aplicações ao texto (e.g. diálogos, descrição) para as sequências em que se encontra o personagem.

Outra questão abordada por Eisner (1989, p. 125) são os aspectos relacionados com a escrita, informando o contexto da imagem ou a sua história, já que a variação do contexto (e.g. um fugitivo que esteja escapando da policia) pode modificar a intenção da mensagem ou seu significado.

Portanto, os resultados alcançados através dos diferentes modos de representar a sequência com ou sem texto, constatam que as duas maneiras podem acrescentar diferentes significados às sequências.

Segundo Eisner (1989, p. 127) encontramse algumas características mais incidentes que outras. Dessa maneira, as imagens como cenário e ação aparecem com maior frequência, as abstrações são outro fator constante nas $16^{\circ}$ Ergodesign - Congresso Internacional de Ergonomia e Usabilidade de Interfaces Humano Tecnológica: Produto, Informações Ambientes Construídos e Transporte

$16^{\circ}$ USIHC - Congresso Internacional de Ergonomia e Usabilidade de Interfaces Humano Computador

CINAHPA | 2017 - Congresso Internacional de Ambientes Hipermídia para Aprendizagem.

representações através de sons (e.g. Boom; Pow; Bang; Puff; Click;) e no cenário. O uso da escrita/texto caracteriza o diálogo e a sequência de tal modo nos quadrinhos, que o texto introdutório se utiliza para marcar a passagens de tempo e variações de locais.

\subsection{Sequência Pictórica de Procedimento (SPP)}

Eisner (1989, p. 136) delimita arte sequêncial em duas funções gerais: instrução e entretenimento. Existindo uma sobreposição de tais categorias por haver uma sequência expositiva das imagens.

Para os quadrinhos de entretenimento expressos por meio de imagens retratadas sem o uso de palavras em suas representações, é necessário existir mensagens profundas e com certa carga emocional em suas ilustrações. Ao contrário da arte sequêncial, aplicada em instruções, que se divide em duas características: os técnicos e os condicionadores de atitudes (EISNER, 1989, p. 141).

Inicialmente os quadrinhos técnicos, são compostos por sequências de procedimentos que demonstrem o aprendizado dos usuários na execução de uma tarefa ou ação (e.g montagem de uma cadeira), cujo objetivo seja estabelecer uma relação entre o leitor e os procedimentos demonstrados por imagens, descrito da melhor maneira possível a fim de representar o procedimento, seja de acordo com a perspectiva do leitor ou conforme se organiza os componentes da sequência, através de textos, balões/imagens, com a realização da familiarização do usuário apoiado em suas experiências, algo que a arte sequêncial possibilita realizar.

A função de condicionar atitudes, o leitor relaciona o seu aprendizado por imitação, com a sua dedução limitando-se a experiências pessoais, o tempo destinado a examinar, assimilar e imaginar o processo da ação é ilimitado, não se restringindo a formas especificas como a fotografia, mas uma generalização da arte que permite o seu exagero que possa estar influenciando com uma maior rapidez o leitor (EISNER, 1989, p. 140-141).
Realização:

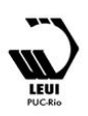




\section{$16^{\circ}$ \\ ERGODESIGN USIHC CINAHPA}

O termo arte sequêncial utilizado em quadrinhos difere da definição encontrada na área do Design, enquanto os quadrinhos utilizam o termo para definir imagens sendo um meio de entretenimento/técnica, o design define o termo como sendo a representação de instruções visuais, denominada sequência pictórica de procedimento.

Para Spinillo (2001) autora que delimita o termo SPP define como:

\begin{abstract}
“O design de sequências pictóricas de procedimentos pode ser considerado uma atividade de resolução de problemas, no sentido que o designer deve propor/buscar soluções para representar de forma eficaz uma série de passos através de ilustrações. Tais soluções são desenvolvidas durante o processo de design” (SPINILLO, 2001, p. 33).
\end{abstract}

Diferenciando do termo instruções visuais que é mais abrangente. Utilizou-se a definição de Spinillo (2001) para Sequências Pictóricas de Procedimentos (SPPs), por considerar uma representação procedimental, por uma série de passos, prioritariamente por meio das ilustrações.

\section{Estilo de Ilustração}

De acordo com a Enciclopédia de Comunicação, ilustração é definida como qualquer imagem que 'acompanha um texto, representada com os mais variados tipos e formas de expressão (DE COMUNICAÇÃO, 2015, p. 651). Assim para Gombrich (1995, p.5) essa variação visual, o estilo é o fator principal para se realizar essa diferenciação entre as representações.

O estilo são as suas características, seja através de escola de artes ou de métodos de descrição que objetivam agrupar, organizar e identificar diferentes técnicas utilizadas constantemente para realizar a distinção dos estilos de uma paisagem chinesa ou holandesa, por exemplo (GOMRBRICH, 1995).

O estilo compreende-se por diversas ideias, desde temperamento/personalidade, preferência pessoas/artista, movimento ou até escolas de arte ou períodos históricos (GOMBRICH, 1995). $16^{\circ}$ Ergodesign - Congresso Internacional de Ergonomia e Usabilidade de Interfaces Humano Tecnológica: Produto, Informações Ambientes Construídos e Transporte

$16^{\circ}$ USIHC - Congresso Internacional de Ergonomia e Usabilidade de Interfaces Humano Computador

CINAHPA | 2017 - Congresso Internacional de Ambientes Hipermídia para Aprendizagem.

A palavra estilo pode ser tudo o que se consegue reunir, seja o temperamento ou personalidade, assim como todas as preferências de determinada pessoa ou artista, podendo ser estilo de época ou estilo do artista, e, assim, quando uma mudança é mais notável, diz-se que é "estilizada" (GOMBRICH, 1995, p. 55).

Para Anzolch (2009, p. 16), o estilo não é algo encontrado no campo da linguística em uma frase, discurso ou na própria gramática, mas presente no campo das artes. $\mathrm{O}$ "estilo é algo que se acrescenta ao código de base do objeto".

Ressalta que no campo da ciência exata o estilo surge como um modo de compreender ou solucionar determinado problema. É o estilo aplicado a determinado objeto, e essa é a maneira mais sucinta de visualizar as características do estilo, sem impedir, no entanto, que os códigos sejam abstratos, como distribuições e proporções, de modo a criar as mais diferentes formas de representação, originando uma sintaxe própria, que pode ser marcante e inconfundível em relação a outros objetos (ANZOLCH, 2009).

Para o campo visual, Dondis (1997, p. 161) determina o estilo como uma "Síntese visual de elementos e técnicas, sintaxe, inspiração, expressão e finalidade básica", a melhor maneira de distinguir os estilos e observar como a categoria ou classe de expressão visual se manifesta.

Dondis (1997, p. 162-163) comenta que os códigos estilísticos acabam se tornando um detalhe mais sutil do que apenas convenções para o controle: "as variantes técnicas podem servir para identificar a individualidade estilística”. Dessa observação direta consegue-se distinguir os estilos e períodos das representações.

O surgimento de diversos períodos estilísticos, como o bizantino, o renascentista, o impressionista, o dadaísta, o gótico, o vitoriando, entre outros, é marcado por aplicação de diferente técnica a cada movimento, o que possibilita a distinção dos períodos. Apenas com a realização de uma análise mais ampla de cada momento é que se pode caracterizar os diferentes estilos e o que,
Realização:

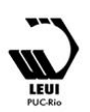




\section{$16^{\circ}$ \\ ERGODESIGN USIHC CINAHPA}

especificamente, representa o artista individualmente (DONDIS, 1997, p. 163).

Consequentemente o estilo é como um ingrediente ou qualidade possibilitando a distinção do individuo ou de um grupo de pessoas, da mesma forma a linguagem pictórica o estilo aplicase a todos os meios de produção incluindo a fotografia. $\mathrm{O}$ estilo pode assumir as mais variadas formas e recursos, como representações em horizontais, verticais, a relação espacial, o contraste de tons entre outros, portanto a categoria estilo pode ser considerada com o mais evasivo de todos, não consistindo uma tarefa fácil a realização da sua descrição em palavras (TWYMAN, 1985, p. 282).

Para Twyman (1985, p. 284-285), a abordagem propostas por Ashwin (1979) identifica algumas variáveis para o estilo de ilustração, características estilísticas baseando na presença ou ausência de tais variáveis. $\mathrm{O}$ autor ainda acrescenta que tais variáveis atende a ilustração, mas poderiam ser adaptadas para que atendessem a outros tipos de linguagem.

Ashwin (1979) apresenta o termo estilo com relação a ilustração contemporânea, o qual não consegue relacionar a palavra estilo com a imagem gráfica, apenas se faz com relação aos períodos históricos ou artísticos (e.g clássico impressionista, surrealista). Observa que o estilo na história da arte busca ser "retrospectiva do que pragmática, preocupando-se com a mudança de época, cíclica ou evolutiva" (ASHWIN, 1979, p.51).

De tal maneira, as decisões para formação da representação são realizadas pelo próprio ilustrador, determinando as características estilísticas atribuídas ao desenho. As decisões, consciente ou inconscientemente, ocorrem de maneira espontânea e, por meio delas, a avaliação do ilustrador e na ilustração. (ASHWIN, 1979, p. 52).

Por todos os aspectos mencionados pelos autores, pode-se caracterizar o estilo como um conjunto de características relacionadas a um $16^{\circ}$ Ergodesign - Congresso Internacional de Ergonomia e Usabilidade de Interfaces Humano Tecnológica: Produto, Informações Ambientes Construídos e Transporte

$16^{\circ}$ USIHC - Congresso Internacional de Ergonomia e Usabilidade de Interfaces Humano Computador

CINAHPA | 2017 - Congresso Internacional de Ambientes Hipermídia para Aprendizagem.

objeto, seja de aspectos comportamentais ou temporais. Assim o Estilo é algo acrescentado ao objeto, como um acessório que faz a diferenciação da representação, com as demais que está sendo relacionada.

\subsection{Estilo de ilustração visual em Sequências Pictórica de Procedimentos}

As instruções são fundamentais em nosso meio. Podem ser encontradas em diversas áreas com naturezas distintas de materiais educativos, cujo objetivo é ensinar a população, como em informativos destinados à saúde, como forma de divulgação de causas, sintomas e tratamentos de doenças ou de métodos contraceptivos. (MAIA, 2005, p. 34).

Itiro (2005, p, 295) apresenta o texto como uma função primordial nas instruções, por conter maiores informações e apresentá-las de maneiras mais objetiva, para que possa auxiliar as pessoas a sanar as dúvidas especificas.

A principal vantagem da utilização de imagem para transmitir uma informação está na aproximação visual do conteúdo com o objeto real. A representação de um homem, por exemplo, possui maior proximidade da realidade que a própria palavra "homem". Diversas pesquisas demonstram a superioridade na compreensão de conteúdos representados por símbolos em relação às instruções verbais. (ITIRO, 2005, p. 298).

Portanto com base nessas afirmações, podemos classificar que para desenvolver uma SPPs é necessário: Informação/conteúdo - o que será apresentado seja por meio de imagens e/ou textos; Ilustrações/Imagens - as representações visuais, com as mais distintas técnicas e formas; Instruções - com a demonstração dos conteúdos, com o conjunto de textos e/ou imagens para a realização do procedimento. Portanto, o estilo encontra-se no meio da intercessão desses três tópicos, de modo que as variações do estilo encontram-se em diversas outras áreas do conhecimento (e.g. arte, arquitetura, cultura, design, moda, música, entre outras), assim como nas SPPs podem ser identificadas, conforme
Realização:

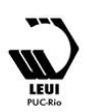




\section{$16^{\circ}$ \\ ERGODESIGN USIHC CINAHPA}

demonstra a Figura 1.

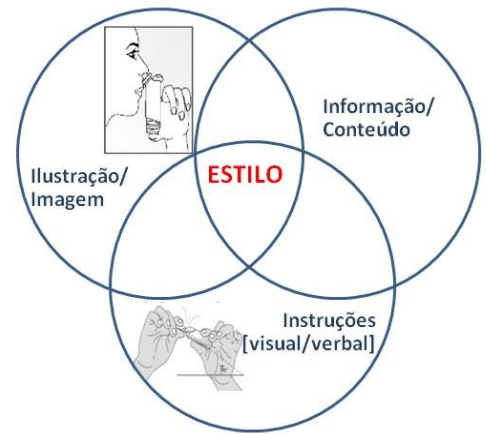

Figura 01 - Representação Gráfica Síntese (RGS). Fonte: Elaboração do autor.

Informações instrucionais elaboradas por meio de ilustrações, em que Spinillo (2001, p. 32) define como Sequências Pictóricas de Procedimentos (SPP), estão presentes em muitos produtos comercializados no mundo inteiro. Esses documentos, manuais, folhetos, cartazes, têm por objetivo auxiliar o usuário, por meio de imagens instrucionais, a operar e utilizar o produto a que se referem (e.g. eletrônicos, eletrodomésticos).

Segundo Spinillo (2001) classifica a ordem do estilo com relação a uma Sequência Pictórica de Procedimento, podem ser delimitados com as seguintes variações: fotográficas, desenho, esquemático e sombra.

Contudo essa variação faz unicamente a separação por técnicas empregadas em sua representação, não descrevendo o estilo em si, com relação a sua composição dos elementos e/ou sua disposição nas imagens instrucionais.

\section{Método}

A metodologia utilizada para esse levantamento foi o estudo analítico, por possibilitar explorar o tema abordado, assim como verificar os estilos em SPPs existentes em bulas de medicamentos.

Descreveremos a amostra verificada, assim como a forma que foi avaliada, por meio da composição de dois modelos, como forma de descrever o estilo visual. A seguir detalharemos a amostra, os modelos utilizados, assim como a forma que será verificada os resultados alcançados com o estudo. $16^{\circ}$ Ergodesign - Congresso Internacional de Ergonomia e Usabilidade de Interfaces Humano Tecnológica: Produto, Informações Ambientes Construídos e Transporte

$16^{\circ}$ USIHC - Congresso Internacional de Ergonomia e Usabilidade de Interfaces Humano Computador

CINAHPA | 2017 - Congresso Internacional de Ambientes Hipermídia para Aprendizagem.

\subsection{Amostra do estudo analítico}

A amostra será composta por bulas digitais, disponibilizadas pelo bulário eletrônico, site desenvolvido pela ANVISA, em que qualquer pessoa pode ter acesso, bastando apenas ter uma conexão com a internet, para realizar a sua consulta às bulas, antes de realizar a compra do medicamento. O sistema disponibiliza a bula configurada em PDF (portable document format) com o formato A4 (21 x 29,7 cm), possibilitando a sua impressão, caso necessário para a sua consulta.

A verificação individual das bulas ocorreu em dois momentos: inicialmente com a separação das bulas com algumas imagens e/ou ilustração e como segunda etapa compostas de modo mais detalhado a sua constatação das bulas que possuem não SPPs, descartando as representações que não caracterizassem uma sequência instrucional.

\subsection{Modelos utilizados para análise.}

Com o objetivo de avaliar o estilo, foram utilizados para descrever individualmente as SPPs em bulas com base em dois modelos: Spinillo (2001) e Ashwin (1979).

O primeiro modelo Spinillo (2001), buscar identificar os elementos presente nas SPPs, a análise se distribuí em oito categorias: apresentação do texto, disposição da sequência, orientadores de leitura, elemento de separação visual, elementos simbólicos, elementos enfáticos, estilo de ilustração e representação da figura, conforme detalha o Quadro 1. Classificada da seguinte maneira: (1) Apresentação do texto relação que se faz do texto à ilustração, maneira de disponibilizar o texto: legenda, quando a ilustração se encontra no interior do texto; rótulo, texto é inserido na ilustração; texto corrido;

(2) Disposição da sequência - as ilustrações podem ser organizadas de forma horizontal, vertical, oblíqua, ramificada ou circular;

(3) Orientadores de leitura - são caracterizados pelos elementos que auxiliam na leitura da sequência, como números e letras; (4) Elementos de separação visual - elementos gráficos que conduzem a separação da ilustração na SPP, como 


\section{$16^{\circ}$ \\ ERGODESIGN USIHC CINAHPA}

$16^{\circ}$ Ergodesign - Congresso Internacional de Ergonomia e Usabilidade de Interfaces Humano Tecnológica: Produto, Informações Ambientes Construídos e Transporte

$16^{\circ}$ USIHC - Congresso Internacional de Ergonomia e Usabilidade de Interfaces Humano Computador

CINAHPA | 2017 - Congresso Internacional de Ambientes Hipermídia para Aprendizagem. bordas, espaços ou linhas; (5) Elementos

simbólicos - linguagem de convenção utilizada na representação, como seta para direção ou barra diagonal para caracterizar negação; (6) Elementos enfáticos - meios utilizados para chamar a atenção do leitor para a SPP ou realçar detalhes na ilustração, com as variações de cores e formas; (7) Estilos de ilustração - variações empregadas para representar a SPP com relação à técnica utilizada para compor a ilustração: esquemático, desenho, fotográfico e sombra; (8) Representação da figura: forma de composição da ilustração, classificada como completa e incompleta, ou seja, parcial.

\begin{tabular}{|c|c|}
\hline Categorias & Sub-Categorias \\
\hline $\begin{array}{l}\text { Apresentação } \\
\text { do texto }\end{array}$ & $\begin{array}{l}\text { Legenda } \\
\text { Texto corrido } \\
\text { Rótulo }\end{array}$ \\
\hline $\begin{array}{l}\text { Disposição da } \\
\text { sequência }\end{array}$ & $\begin{array}{l}\text { Horizontal } \\
\text { Vertical } \\
\text { Obliqua } \\
\text { Circular } \\
\text { Ramificação }\end{array}$ \\
\hline $\begin{array}{l}\text { Orientadores de } \\
\text { leitura }\end{array}$ & $\begin{array}{l}\text { Letras } \\
\text { Números } \\
\text { Setas }\end{array}$ \\
\hline $\begin{array}{l}\text { Elemento de } \\
\text { separação visual }\end{array}$ & $\begin{array}{l}\text { Bordas } \\
\text { Espaço } \\
\text { Linhas }\end{array}$ \\
\hline $\begin{array}{l}\text { Elementos } \\
\text { simbólicos }\end{array}$ & $\begin{array}{l}\text { Barra diagonal } \\
\text { Setas }\end{array}$ \\
\hline $\begin{array}{l}\text { Elementos } \\
\text { enfáticos }\end{array}$ & $\begin{array}{l}\text { Cores } \\
\text { Formas }\end{array}$ \\
\hline $\begin{array}{l}\text { Estilo de } \\
\text { ilustração }\end{array}$ & $\begin{array}{l}\text { Desenho } \\
\text { Esquemático } \\
\text { Fotográfico } \\
\text { Sombra } \\
\end{array}$ \\
\hline $\begin{array}{l}\text { Representação } \\
\text { da figura }\end{array}$ & $\begin{array}{l}\text { Ilustração parcial } \\
\text { Ilustração completa }\end{array}$ \\
\hline
\end{tabular}

Quadro 1 - Modelo de análise: SPPs. Fonte: SPINILLO, 2001.

O segundo modelo de análise, tem como objetivo especificar as variáveis do estilo visual, assim como realizar uma extensão do primeiro modelo descritivo com relação ao estilo.

Ashwin (1979, p. 52) propõe uma análise para verificar as características estilísticas no campo semântico da ilustração, identificando sete elementos do estilo: (1) Consistência, responsável pelo desenvolvimento da imagem através da uniformidade da linha, espessura e peso;

(2) Gama é imposta pelo ilustrador com a expansão ou restrição de técnicas utilizadas na ilustração; (3) Enquadramento é a forma que está disposta os elementos na apresentação da imagem; (4) Posicionamento está relacionado com a composição da imagem a partir da disposição dos elementos; (5) Proxêmica constitui da distancia implica do espectador com relação a imagem, através da sua escala (aumentando/diminuindo); (6) Cinética, são características que o próprio ilustrador reforça na imagem seja com o uso de linhas ou traços que caracterize movimento na ilustração; (7) Naturalismo classificada como um conjunto das demais, consistindo na relação ao objeto em si, com a sua aproximação do real e o seu distanciamento como não-naturalista.

O autor classifica a variável visual, por meio do posicionamento entre polos opostos, conforme o detalhamento da imagem, proporcionado pelo estilo, quando associadas à ilustração contemporânea, ao significado da palavra com relação à imagem gráfica.

A classificação que o autor propõe, apresenta as variáveis por meio de polos extremos, contudo nota que algumas representações não são bem definidas em uma única extremidade, já que avaliação do estilo em uma SPP considera não apenas uma única imagem como é realizado por Ashwin (1979), mas um conjunto para a formação de uma SPP. Portanto, optou-se realizar a descrição do estilo em uma escala Likert ou escala de medida, já que algumas representações não se posicionam em apenas uma extremidade (Polo), fazendo-se necessário ter um meio-termo para a descrição com base nas características das SPPs, já que esse modelo avaliativo é muito utilizado em pesquisas empíricas. A escala Likert é composta por uma variável numérica de 1 a 5 , de modo que o número 3 é o posicionamento neutro na escala, ocasião em que não posiciona a nenhum polo específico conforme demonstra o quadro 2 .
Realização:
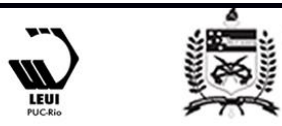


\section{$16^{\circ}$ \\ ERGODESIGN USIHC CINAHPA}

$16^{\circ}$ Ergodesign - Congresso Internacional de Ergonomia e Usabilidade de Interfaces Humano Tecnológica: Produto, Informações Ambientes Construídos e Transporte

$16^{\circ}$ USIHC - Congresso Internacional de Ergonomia e Usabilidade de Interfaces Humano Computador

CINAHPA | 2017 - Congresso Internacional de Ambientes Hipermídia para Aprendizagem.

\begin{tabular}{l|l|l|l|l|l|l|l}
\cline { 2 - 6 } & \multicolumn{7}{c}{ POLOS } \\
\hline Consistência & Homogênea & & & & & & Heterogênea \\
\hline Gama & Expandida & & & & & & Restritiva \\
\hline Enquadramento & Conjuntiva & & & & & & Disjuntivo \\
\hline Posicionamento & Simétrico & & & & & & Casual \\
\hline Proxêmica & Perto & & & & & & Distante \\
\hline Cinética & Dinâmico & & & & & & Estático \\
\hline Naturalismo & Naturalista & & & & & & Não-Naturalista \\
\hline
\end{tabular}

Quadro 2 - Modelo de análise: Estilo de ilustração. Fonte: Elaborado pelo autor baseado em ASHWIN, 1979.

\subsection{Análise dos resultados}

Os resultados obtidos com os dois modelos, serão tratados de modo quantitativos. A tabulação dos dados foi realizada diretamente em planilhas do Excel, para obter os valores para todas as categorias verificadas por meio dos modelos de Spinillo (2001) e Ashwin (1979).

\section{Resultados}

Os resultados obtidos com o estudo constatou a quantidade de 2534 bulas cadastradas até a data de 10 de fevereiro de 2016, nessa abordagem preliminar o volume de 422 bulas com algum tipo de imagem constituindo ou não uma sequência procedimental. Após o levantamento mais detalha das representações, foram descartados os documentos que nãoconstituia uma sequência instrucional, após essa nova avaliação delimitou-se a amostra a quantia de 277 bulas com SPPs cerca de $10 \%$ da amostra total disponível no bulário eletrônico.

A verificação por meio dos dois modelos aplicados as bulas se mostraram bem satisfatório, observa-se que o primeiro modelo destinado a avaliação das SPPs que consiste em delimitar as características predominantes, através do modelo proposto por Spinillo (2001), para a análise completas das sequências instrucionais, da qual faz a verificação das características essenciais em uma SPP como: textos, símbolos e a composição da ilustração presente na sequência. O segundo modelo elaborado por Ashwin (1979) busca realizar o seu detalhamento do estilo de ilustração por meio de polos, a fim de identificar as características representadas e a variação das técnicas empregadas para sua composição. A seguir serão detalhados os resultados obtidos com os dois modelos descritivos verificando as características com maior incidência levantada na amostra.

\subsection{Detalhamentos das categorias abordadas no modelo para Sequências Pictórica de Procedimentos}

Os resultados alcançados com o modelo de $n^{\circ} 1$, utilizado para a descrição dos elementos presentes nas SPPs, a qual é dividida em oito categorias: apresentação de textos, disposição da sequência, orientadores de leitura, elementos de separação visual, elementos simbólicos, elementos enfáticos, estilo de ilustração, representação da figura. Assim os valores numéricos obtidos com a amostra teve pesos iguais para todas as categorias abordadas, com o valor de 1 (um) indicando a presença de tais informações e o número 0 (zero) para a sua ausências.

A somatória das sub-categorias para cada grupo de variação, obteve o número $(\mathrm{t}=2244)$ que ao dividi-los com a quantidade de bulas avaliadas na amostra $(\mathrm{a}=277)$ tem-se uma média de $(\mathrm{m}=8.10)$ para cada bula avaliada, assim o modelo demonstra que para cada categorias (e.g. apresentação de texto) está presente uma das opções disponibilizada (e.g. legenda) presente nas SPPs (Quadro 3).

Em relação à apresentação do texto, o item legenda $(n=133)$ destaca-se na amostra, seguido do item texto corrido $(\mathrm{n}=97)$, consistindo no uso das imagens no interior do texto, como forma de detalhar o procedimento por meio da escrita como um apoio à imagem instrucional, informações necessárias para complementar como ações e/ou movimento, modo de preparo (e.g. água morna), descartes da medicação entre outros conteúdos não explicito na representação visual, a fim de completar o entendimento do leitor para realizar a tarefa. 
$16^{\circ}$ Ergodesign - Congresso Internacional de Ergonomia e Usabilidade de Interfaces Humano Tecnológica: Produto, Informações Ambientes Construídos e Transporte

$16^{\circ}$ USIHC - Congresso Internacional de Ergonomia e Usabilidade de Interfaces Humano Computador

CINAHPA | 2017 - Congresso Internacional de Ambientes Hipermídia para Aprendizagem.

\begin{tabular}{|c|c|c|c|}
\hline Categorias & Sub-categorias & Resultado & Total \\
\hline \multirow{3}{*}{$\begin{array}{l}\text { Apresentação } \\
\text { do texto }\end{array}$} & Legenda & 133 & \multirow{3}{*}{288} \\
\hline & Texto corrido & 097 & \\
\hline & Rótulo & 058 & \\
\hline \multirow{5}{*}{$\begin{array}{l}\text { Disposição da } \\
\text { sequência }\end{array}$} & Horizontal & 098 & \multirow{5}{*}{295} \\
\hline & Vertical & 196 & \\
\hline & Obliqua & 001 & \\
\hline & Circular & 000 & \\
\hline & Ramificação & 000 & \\
\hline \multirow{3}{*}{$\begin{array}{l}\text { Orientadores } \\
\text { de leitura }\end{array}$} & Letras & 035 & \multirow{3}{*}{239} \\
\hline & Números & 204 & \\
\hline & Setas & 000 & \\
\hline \multirow{3}{*}{$\begin{array}{l}\text { Elemento de } \\
\text { separação } \\
\text { visual }\end{array}$} & Bordas & 173 & \multirow{3}{*}{456} \\
\hline & Espaço & 252 & \\
\hline & Linhas & 031 & \\
\hline \multirow{2}{*}{$\begin{array}{l}\text { Elementos } \\
\text { simbólicos }\end{array}$} & Barra diagonal & 020 & \multirow{2}{*}{244} \\
\hline & Setas & 224 & \\
\hline \multirow{2}{*}{$\begin{array}{l}\text { Elementos } \\
\text { enfáticos }\end{array}$} & Cores & 065 & \multirow{2}{*}{126} \\
\hline & Formas & 061 & \\
\hline \multirow{4}{*}{$\begin{array}{l}\text { Estilo de } \\
\text { ilustração }\end{array}$} & Desenho & 252 & \multirow{4}{*}{319} \\
\hline & Esquemático & 040 & \\
\hline & Fotográfico & 026 & \\
\hline & Sombra & 001 & \\
\hline \multirow{3}{*}{$\begin{array}{l}\text { Representação } \\
\text { da figura }\end{array}$} & Ilustração parcial & 189 & \multirow{2}{*}{277} \\
\hline & Ilustração completa & 088 & \\
\hline & Total & & 2244 \\
\hline
\end{tabular}

Quadro 3 - Resultado do modelo: SPPs.

Fonte: Elaborado pelo autor baseado em SPINILLO, 2001

Para a categoria disposição da figura, o maior índice observado são a estrutura da SPP no modo vertical $(\mathrm{n}=198)$, seguido da horizontal com $(\mathrm{n}=098)$, oblíqua com apenas um resultado $(\mathrm{n}=001)$ e as sub-categorias circular e ramificada não foram constatadas na amostra. Nota-se que em algumas bulas verificadas a presença de duas composições horizontal e vertical $(n=017)$ presente na mesma representação.

Os orientadores de leitura destacam-se com as maiores incidência os guias numéricos $(n=204)$, em seguida as letras $(n=035)$ e os orientadores por setas $(n=000)$ não foram localizados nas bulas com relação a este objetivo. Observa-se que em algumas SPPs foram encontrados os dois guias de leitura, números e letras $(n=011)$ na mesma representação com forma de orientação dos passos e sub-passos em uma mesma sequência procedimental.
Como forma de delimitar a SPP, os elementos de separação visual, dos quais subdividem em três categorias, destacando inicialmente o espaço $(\mathrm{n}=252)$ presente em aproximadamente $91 \%$ das bulas verificadas, a borda $(n=173)$ como elementos limitador da representação e por último a linha $(\mathrm{n}=031)$. Contudo, verifica que o uso do espaço em conjunto com a borda $(n=149)$ forma os recursos presentes em mais da metade das bulas, cerca de $53 \%$ da amostra.

Os elementos simbólicos são categorias destinadas para a contribuição visual nas SPPs, assim está categoria destaca-se para o uso das setas $(\mathrm{n}=224)$ presente em $80 \%$ da amostra como item para a demonstração de movimento e/ou indicação no procedimento (e.g. girar, puxar, apertar, abrir entre outros), outra unidade simbólica, a barra $(\mathrm{n}=020)$ como forma de indicar proibições e/ou a divisão do procedimento como sub-passos para a mesma sequência instrucional.

Os meios acrescentados em uma SPP como o objetivo de realizar um destaque a imagem, são classificada como elementos enfáticos, as duas sub-categorias alcançaram resultado bem próximos uma das outras, as Cores $(n=065)$ com a sua variação de paletas de cores como forma de realçar a imagem, o mesmo ocorre nas instruções monocromática com a utilização do branco, cinza e/ou preto e para a Formas $(n=061)$ desenvolvida através da ênfase, seja ela nos elementos geométricos (e.g. triângulo, quadrado), formas orgânicos (e.g. linhas, pontos) e elementos pré-definidos (e.g. seta, barra). A conexão desses dois grupos: cores e formas ( $\mathrm{n}=022)$, também estão presentes nessa categoria transformando em um conjunto de melhor destaque a SPP ilustrada.

A classificação do estilo de ilustração, destinado pela variação da representação, alcançou com o desenho $(\mathrm{n}=252)$ cerca de $91 \%$ da amostra verificada (Figura 5.12), a representação esquemática $(n=040)$, fotográfica $(n=026)$ e sombra $(\mathrm{n}=001)$ classificado como o estilo de menor evidência presente nas SPPs de Bulas. Nota que a variação das categorias também ocorreu em conjunto com outros estilos visuais, a fim de 


\section{$16^{\circ}$ \\ ERGODESIGN USIHC CINAHPA}

classificar o nível de detalhes por meio da representação, alcançando as seguintes condições: desenho/esquemático $(\mathrm{n}=021)$, desenho/ fotográfico $(n=017)$ sendo classificado conforme grau de aproximação com o objeto real, ou seja, o estilo fotográfico. $\mathrm{O}$ desenho/sombra $(\mathrm{n}=001)$ se destaca como o único em toda a amostra, também é possível verificar a presença da representação esquemático/fotográfico ( $\mathrm{n}=003)$, como os elementos ilustrativos para complementar o entendimento das instruções ou a junção dos dois estilos.

Por fim, a última categoria abordada no modelo à representação da figura, divide-se em duas maneiras: a ilustração parcial $(\mathrm{n}=189) \mathrm{com}$ $68 \%$ da amostra total, classificada de tal maneira por realizar a representação de forma parcial, a partir dos critérios estabelecidos pelo próprio ilustrador e/ou design responsável pela concepção da SPP e/ou da utilização dos elementos

delimitadores (e.g. bordas e/ou espaços), também uma das categoria presente no modelo, apresentado como elementos de separação visual. A ilustração completa $(n=088)$, categorizada como a representação total da imagem presente na SPP não aplicando a nenhum desses fatores, como ocorre para a representação parcial.

\subsection{Detalhamentos das categorias abordadas no modelo para Estilo de ilustração}

Os resultados obtidos com o modelo $\mathrm{n}^{\circ} 2$, proposto por Ashwin (1979), tem como objetivo a descrição do estilo de ilustração, conforme o autor delimita como as características do ilustrador, por constantes decisões para determinar o caráter estilístico ocorrendo de forma consciente e inconsciente realizada pelo ilustrador (ASHWIN, 1979). Entretanto, Dondis (1997) classifica que a composição do estilo visual, é desenvolvida de acordo com a técnica empregada na representação.

A fim de delimitar as características do estilo Ashwin (1979) estrutura o seu modelo descritivo em sete variáveis visuais, por meio da sua classificação entre os polos opostos como forma de descrever o estilo de ilustração em uma sequência de imagens. Assim os resultados obtidos $16^{\circ}$ Ergodesign - Congresso Internacional de Ergonomia e Usabilidade de Interfaces Humano Tecnológica: Produto, Informações Ambientes Construídos e Transporte

$16^{\circ}$ USIHC - Congresso Internacional de Ergonomia e Usabilidade de Interfaces Humano Computador

CINAHPA | 2017 - Congresso Internacional de Ambientes Hipermídia para Aprendizagem.

se assemelham ao primeiro modelo, em que para cada variável do modelo atribuía-se o valor numérico 1 (um), com um total de 7 (sete) para cada SPP verificada, a somatória $(\mathrm{n}=277)$ classificado para cada variável do modelo verificada conforme está distribuída no Quadro 4.

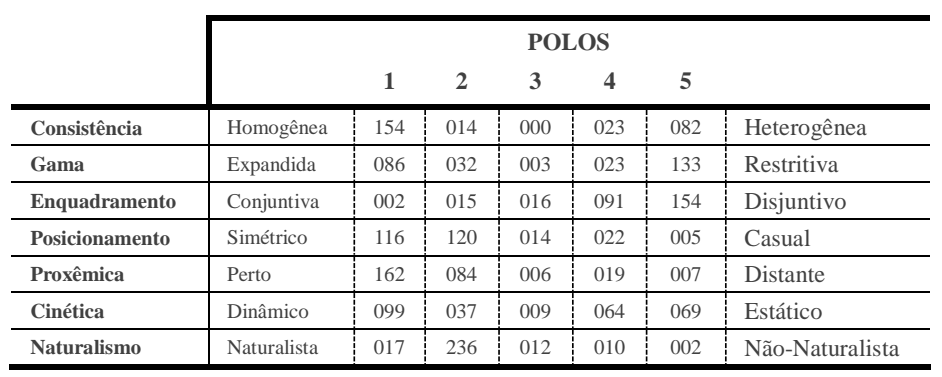

Quadro 4 - Resultado do modelo: Estilo de ilustração. Fonte: Elaborado pelo autor baseado em ASHWIN, 1979.

Inicialmente a variação visual, Consistência, caracterizando pela composição da forma da imagem, destaca-se para a homogênea $(n=154)$ e $(n=014)$, consistindo como uma unidade nas representações em SPPs obteve como resultado neutro $(n=004)$ quantidade relativamente pequena quando confrontada com a amostra total. A variável heterogênea $(n=082)$ e $(n=023)$, ao todo $(\mathrm{n}=105)$, consiste na diversidade entre as imagens, ou seja, a diferenças umas das outras.

Para a categoria Gama, compreendem-se como as técnicas empregadas na representação visual destacando os resultados alcançados com o polo Restrito $(n=133)$ e ( $n=023)$, num total $(\mathrm{n}=156)$, conforme a Figura 5.24, representado pela variação das técnicas utilizadas, assim também classificam os resultados neutros $(\mathrm{n}=003)$ considerados mínimos para a amostra avaliada. $\mathrm{O}$ polo oposto, categorizado pelas diferentes técnicas empregadas na representação, denominado Expandido $(\mathrm{n}=086)$ e $(\mathrm{n}=032)$ ao todo $(\mathrm{n}=120)$, assim soma de tais características, não alcança os resultados obtidos com o polo Restrito.

O Enquadramento caracteriza-se pela composição do fundo da imagem, ou seja, constitui por meio da ampliação ou redução dos elementos configurados ao plano. $\mathrm{O}$ polo denominado disjuntivo $(n=154)$ e $(n=091)$, com o total $(n=245)$ aproximadamente $88 \%$ da amostra com essas 


\section{$16^{\circ}$ \\ ERGODESIGN USIHC CINAHPA}

propriedades, consiste em realizar a separação das características principais da imagem com o fundo, de modo que não atrapalhe o seu entendimento. Nesta categoria, assim como as demais, obteve resultados baixo na classificação neutra $(n=016)$, para oposto, denominado como conjuntivo $(n=002)$ e $(n=015)$, pelo excesso de elementos no plano dificultando o seu entendimento na imagem.

A categoria Posicionamento na ilustração, destinada para a composição dos elementos visuais em relação a sua posição no plano a qual está sendo representado, ocorre a variação entre simétrica $(n=116)$ e $(n=120)$, total de $(n=236)$ aproximadamente $85 \%$ da amostra avaliada. $\mathrm{O}$ polo neutro $(n=014)$, e na categoria alternativa a casual $(n=005)$ e $(n=022)$ considerada por não priorizar a importância de seus componentes, classificando pela avaliação dispostas por todos os seus elementos em seu plano.

Em relação à Proxêmica da representação, consiste a distância da ilustração com o leitor, por meio da variação da escala de aproximação (perto) ou seu distanciamento (distante). A subcategoria perto $(n=162)$ e $(n=084)$ com um resultado $(n=246)$ aproximadamente $88 \%$ da amostra verificada. As demais subcategorias obtiveram-se índices baixos na amostra com os polos neutro $(n=006)$ e distante $(n=007)$ e $(n=019)$ nessa variável.

A variável visual responsável pela demonstração de movimento, a Cinética ao utilizar em uma SPPs é avaliado a sequência completa de imagens como forma de demonstrar a ação. A categoria é classifica entre dois polos, dinâmica $(n=099)$ e $(n=037)$ com um total $(n=136)$ na amostra e para a outra sub-categoria, a estática $(n=069)$ e $(n=064)$ com a soma $(n=133)$ tornando os resultados bem semelhantes ao primeiro polo. $\mathrm{O}$ polo neutro $(n=009)$ obteve um resultado pequeno, comparado com o resultado total do estudo.

Por fim, a última variação do modelo proposto por Ashwin (1979), Naturalismo, classificado como a maneira de representar o objeto em si, ou seja, a sua distinção entre o real e abstrato na imagem. Os resultados alcançados com o polo naturalista $(n=017)$ e $(n=236)$, classificado $16^{\circ}$ Ergodesign - Congresso Internacional de Ergonomia e Usabilidade de Interfaces Humano Tecnológica: Produto, Informações Ambientes Construídos e Transporte

$16^{\circ}$ USIHC - Congresso Internacional de Ergonomia e Usabilidade de Interfaces Humano Computador

CINAHPA | 2017 - Congresso Internacional de Ambientes Hipermídia para Aprendizagem.

conforme a técnica utilizada para representação da SPPs variando entre fotografia e desenho soma cerca $91 \%$ das bulas com essas características. Contudo o polo oposto que torna as imagens mais abstratas, denominado como não-naturalista $(n=002)$ e $(n=010)$ e o polo neutro $(n=012)$, responsável pelas presenças das duas características em uma mesma SPPs atingiram os mesmo resultados que a amostra.

\subsection{Síntese dos resultados obtidos com os dois modelos avaliativos em bulas}

Os resultados abordados cujo objetivo se delimita em identificar os estilos de ilustração empregados nas bulas de medicamentos brasileiras, a partir do levantamento de dois modelos descritivos: Ashwin (1979) e Spinillo (2001). Contudo este estudo não se limitou apenas aos objetivos especifico que consiste em verificar os estilos de ilustração presentes nas Bulas de medicamentos, mas realizar uma averiguação geral, por meio dos dois modelos utilizados e os pontos em que ambos, não foram alcançados por nenhum dos modelos abordados, seja em relação à Sequência Pictórica de Procedimento ou para o estilo de ilustração, de tal forma detalharemos algumas informações com relação às características que foram constatadas na análise das representações.

As unidades das representações instrucionais são outro fator verificado que para Ashwin (1979) classifica como consistência. Contudo a amostra percebeu-se uma diversidade entre traço e linhas em algumas SPPs.

Observa-se que a representação seccionada (corte), não é categorizada em nenhum dos modelos, contudo Spinillo (2001) detalha como uma representação da figura em duas maneiras completa ou parcial, classificada de acordo com algum objeto ou pela representação do paciente. Contudo esse estilo de representação não se aplica a ilustração seccionada, assim a quantidade de elementos e detalhes a esse tipo de ilustração não é compreendida por todos, necessitando de um conhecimento prévio sobre o tema abordado conforme apresenta a Figura 02, além disso, o nível de detalhes representado na imagem interna é
Realização:

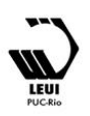




\section{$16^{\circ}$ \\ ERGODESIGN USIHC CINAHPA}

outro fator que pode influenciar o seu entendimento (Figura 03).
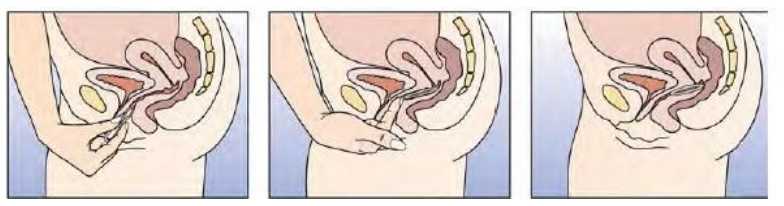

Figura 02 - Representação Seccionada

(Creme vaginal). Fonte: NUVARING, 2013, p. 8.

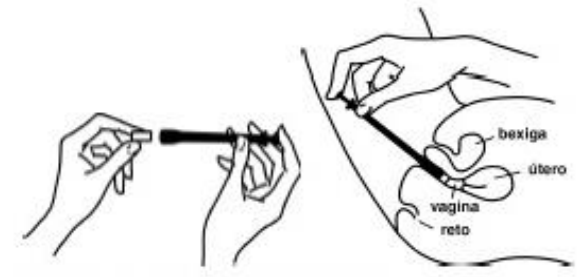

Figura 03 - Representação Seccionada sem detalhes (Creme vaginal). Fonte: CANESTEN, 2015, p. 4

Os elementos visuais que constituíam as SPPs foram observados pelos dois modelos, obtendo um melhor desempenho o proposto por Spinillo (2001), por realizar a classificação dos elementos em duas categorias: simbólicos e enfáticos, o primeiro dividido em barra diagonal e seta e o segundo classificado em cores e formas. Nota que os elementos simbólicos, neste caso a seta, constitui de duas maneiras distintas na realização da sua representação, como elementos de indicação e para a demonstração de movimento, contudo observa que essas duas formas não são padronizadas no âmbito nacional para todas as bulas de medicamento, por meio das RDC $n^{\circ} 140$ de 2003 e $\mathrm{RDC} \mathrm{n}^{\circ} 47$ de 2009 estabelecidas pela ANVISA, contudo o estado do Paraná, como pioneiro no país com a resolução SESA n ${ }^{\circ} 62$ de 2013, destinadas apenas aos medicamentos magistrais, estabelece algumas especificações em relação a instruções visuais como a utilização de seta com elementos para representação de movimento.

Os elementos enfáticos, categorizados em cores pela sua variação a fim de realçar a imagem, para as instruções monocromáticas faz a utilização das cores branca, cinza e preto. Para as formas observa que este último, apresenta uma nomenclatura bem abrangente, realizando a sua limitação pela função de ênfase a SPPs, com o uso $16^{\circ}$ Ergodesign - Congresso Internacional de Ergonomia e Usabilidade de Interfaces Humano Tecnológica: Produto, Informações Ambientes Construídos e Transporte

$16^{\circ}$ USIHC - Congresso Internacional de Ergonomia e Usabilidade de Interfaces Humano Computador

CINAHPA | 2017 - Congresso Internacional de Ambientes Hipermídia para Aprendizagem.

de elementos geométricos (e.g. triângulo, quadrado), formas orgânicas (e.g. linhas, pontos) ou elementos pré-definidos (e.g. seta, barra), entretanto, de modo geral os elementos visuais, têm diversas possibilidades representativas, abarcando inclusive a seta qual esta alocada como elemento simbólico. Assim, como as características enfáticas, o zoom e hipérbole, são outros fatores abordados na amostra como forma de aproximar e/ou detalhar a sequência instrucional, de tal modo, essas propriedades não são incorporadas aos modelos para descrever tanto a SPP como para o estilo de ilustração.

A descrição para movimento na sequência é outro fator observado na amostra, abordado pelo modelo proposto por Ashwin (1979) classificado na categoria cinética constituídas de elementos que fazem alusão à ação como: seta, aspas (Figura 04), linhas (Figura 05) e múltiplas (Figura 06), características que não são classificadas em nenhum dos modelos utilizado nas SPPs.

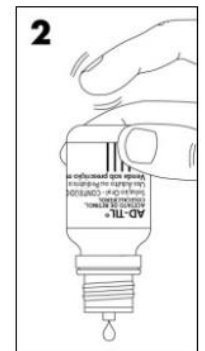

Figura 04 - Representação de movimento (Aspas). Fonte: AD-TIL, 2015, p. 10.

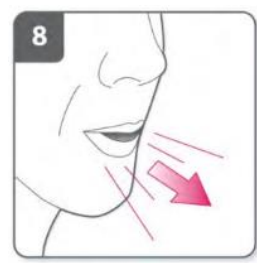

Figura 05 - Representação de movimento (Linhas). Fonte: OMBRIZE, 2015, p. 6.

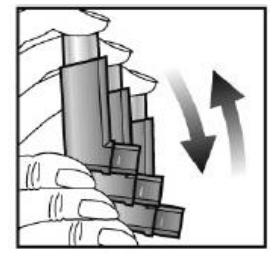

Figura 06 - Representação de movimento (Múltiplos). Fonte: CLENIL COMPOSITUM HFA, 2014, p. 6. 


\section{$16^{\circ}$ \\ ERGODESIGN USIHC CINAHPA}

$16^{\circ}$ Ergodesign - Congresso Internacional de Ergonomia e Usabilidade de Interfaces Humano Tecnológica: Produto, Informações Ambientes Construídos e Transporte

$16^{\circ}$ USIHC - Congresso Internacional de Ergonomia e Usabilidade de Interfaces Humano Computador

CINAHPA | 2017 - Congresso Internacional de Ambientes Hipermídia para Aprendizagem.
Para Gombrich (1995) o estilo é a principal fator que faz a diferenciação entre uma representação da outra, classificada com suas características presente na imagem, e segundo Anzolch (2009), como alguma coisa que é acrescentado ao próprio objeto. Assim a variação do estilo de ilustração, abordado por Spinillo (2001) em seu modelo, destaca-se para a junção de alguns estilos nas SPPs avaliadas com o ocorre na Figura 05 com a mistura do esquemático com o desenho, realizando uma aproximação da imagem real, por meio da variação do estilo baseado em suas técnicas empregadas em uma mesma representação. Para Dondis (1997) considera a técnica aplicada as ilustrações como a forma de classificar o estilo nas representações, assim com base no modelo de Spinillo (2001) e na amostra verificada é possível identificar essas variação por uma escala entre o abstrato (esquemático) aproximação da imagem real (fotográfico).

\section{Considerações finais}

Esta pesquisa se propôs, a descrever o estilo de ilustração contidas nas bulas da qual se destina na realização de tarefas, seja com o preparo e/ou aplicação da própria medicação.

Para o entendimento das ilustrações procedimentais caso não estejam bem representadas será necessário o uso do texto como forma de complementar as informações aplicada por meio da imagem, assim as representação seccionadas ou em corte são necessário além do texto para auxiliar a compreensão da imagem, também requer um conhecimento prévio por parte dos usuários/pacientes para o entendimento do seu conteúdo para a realização da tarefa.

Assim os órgãos que fiscalizam as bulas de medicamentos nacionais poderiam acrescentar uma regulamentação consistente e detalhada, destinando aos laboratórios para a elaboração de Sequências Pictóricas de Procedimentos (SPP) nos fármacos, com o objetivo de melhor representar a tarefa limitando-se a poucas variações de estilo, para representar um mesmo procedimento.
Contudo, vale salientar que além da unidade a própria representação é necessária, uma normatização que regule também outras características que são presentes nas SPPs como: os elementos simbólicos, enfáticos e cores.

- Elementos simbólicos: padronização dos símbolos de convenção utilizados nas representações como: Xis $(\mathbf{X})$ Tick $(\checkmark)$ e Barra (/ ). Assim, com a utilização da seta, deve se realizar a sua diferenciação com relação aos seus objetivos, uma para indicar algo na imagem, para as que buscam demonstrar movimento, ou seja, ação na SPP.

- Elementos de ênfase: padronização das formas (e.g. geométricas) que tenha a função de realizar o destaque ao próprio procedimento, de tal modo que a inclusão do zoom e a hipérbole apenas como recursos para detalhar os passos das SPPs, em que não se consegue visualizar ou compreender na representação normal.

- Cores: delimitar uma palheta de cores, para os desenvolvedores das SPPs, configurando a melhor maneira de contrastar figura fundo com a representação.

Assim, o órgão responsável necessita fiscalizar os laboratórios para o desenvolvimento dessas ilustrações procedimentais, sendo indispensável uma normatização para que os laboratórios possam estar utilizando para o desenvolvimento das SPPs.

Conclui-se que o estudo apresentou de forma quantitativa, as variações de estilos e elementos visuais presentes nas ilustrações procedimentais em bulas de medicamentos, ainda que obtivesse alguns resultados bem satisfatórios com relação à delimitação das representações, necessita uma avaliação em conjunto com usuários/pacientes na realização de tarefa, como forma de verificar se essas características estão sendo representadas de forma clara e objetivas no procedimento. 
$16^{\circ}$ Ergodesign - Congresso Internacional de Ergonomia e Usabilidade de Interfaces Humano Tecnológica: Produto, Informações Ambientes Construídos e Transporte

$16^{\circ}$ USIHC - Congresso Internacional de Ergonomia e Usabilidade de Interfaces Humano Computador

CINAHPA | 2017 - Congresso Internacional de Ambientes Hipermídia para Aprendizagem.

\section{Bibliografia}

AD-TIL. Responsável técnica Rafael de Santis. Jaguariúna: Takeda Pharma Ltda., 2015. Bula de remédio.

ANVISA. Os perigos do uso inadequados de medicamentos. 2007. Disponível em: < http://goo.gl/mtVcP2 > Acesso em 10 de nov. 2015.

Como acessar o Bulário Eletrônico ?.

Disponível em: <goo.gl/Vae5p9> Acesso $10 \mathrm{de}$ fevereiro de 2017.

Bulário Eletrônico. Disponível em: <goo.gl/EFnzHN> Acesso 10 de fevereiro de 2017b.

ANZOLCH, R. Geometria do estilo: genealogia da noção da arquitetura. Tese (Doutorado em Arquitetura). Universidade Federal do Rio Grande do Sul. Porto Alegre, 2009.

ASHWIN, C. The ingredients of style in contemporary illustration: a case study. Information design journal, v. 1, n. 1, 1979. p. 5167

BRASIL. Coletânea de Normas para o Controle Social no Sistema Único de Saúde. Ministério da Saúde, Conselho Nacional de Saúde. 2. ed. Editora do Ministério da Saúde. Brasília, 2006. p. 1-7.

CANESTEN. Responsável técnico Dirce Eiko Mimura. São Paulo: Beyer S.A., 2015. Bula de remédio.

CLENIL COMPOSITUM HFA. Responsável técnica C. M. H. Nakazaki. Santana de Parnaíba: Chiesi Farmacêutica Ltda., 2014. Bula de remédio.

DE COMUNICAÇÃO, ENCICLOPÉDIA INTERCOM. Vol 1, Conceitos. São Paulo: Intercom, p. 547-549, 2010.

DONDIS, D. A. Sintaxe da linguagem visual. 2.ed. São Paulo: Martins Fontes, 1997.
EISNER, Will. Quadrinhos e arte sequêncial.São Paulo. Martins Fontes, 1989.

FUJITA, P. T. L. SPINILLO; C. G.. Design da informação em bulas de medicamento: análise e classificação da estrutura e apresentação gráfica de seu conteúdo textual. Rev Bras Desig Inform, v. 5, n. 3, p. 1-12, 2008.

GOMBRICH, E. H. Arte e ilusão: um estudo da psicologia da representação pictórica. São Paulo: Martins Fontes, 1986, 384p.

HAMMERSCHMITH, C. Tipografia em bulas de medicamentos digitais para acesso ao Bulário Eletrônico em dispositivos de Interação móvel. Dissertação (Mestrado em Design), Programa de Pós-Graduação em Design, Universidade Federal do Paraná, Curitiba, 2014.

ITIRO, I. Ergonomia-projeto e produção. EDGARD BLUCHER, 2 Ed. 2005.

KLAASSEN, C.D. Princípios de toxicologia. In: GILMAN, A.G.et al. Goodman e Gilman: as bases farmacológicas da terapêutica. 7. ed. Rio de Janeiro: Guanabara Koogan, 1985. p.1045-1052. Apud: MARTINS, D. I. Farmacovigilância e Reações adversas aos medicamentos (RAMs). Mundo Saúde, São Paulo, v.24, n.2, p.106-109, 2000.

MAIA, T. C. Conteúdo ou forma? Um estudo sobre a influência da familiaridade com a linguagem pictórica e o conteúdo informacional na compreensão de sequência pictórica de procedimento. Infodesign: Revista Brasileira de Design da Informação, v. 2, n. 1, 2005.

MCCLOUD, S. Desvendando os quadrinhos. São Paulo: M. Books, 1995.

NASACORT. Responsável técnico Silvia Regina Brollo. São Paulo: Sanofi-Aventis Farmacêutica Ltda., 2014. Bula de remédio.

NUVARING. Responsável técnico Cristina Matushima. São Paulo: Schering-Plough Indústria Farmacêutica Ltda., 2013. Bula de remédio.
Realização:

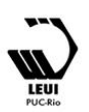


$16^{\circ}$ USIHC - Congresso Internacional de Ergonomia e Usabilidade de CINAHPA

Interfaces Humano Computador

CINAHPA | 2017 - Congresso Internacional de Ambientes Hipermídia para Aprendizagem.

PARANÁ. Secretaria de Estado da Saúde.

Medicamentos manipulados terão bulas padronizadas no Paraná. 2013a. Disponível em: <http://goo.gl/jTwTZ4> Acesso 15 de abril de 2016.

PARANÁ. Secretaria de Estado da Saúde. Resolução SESA no 62. 2013b. Disponível em: <http://goo.gl/46PkLI>. Acesso 15 de abril de 2016.

RDC 47. Resolução da Diretoria ColegiadaAgência nacional de vigilância sanitária. (2009). Disponível em <http://goo.gl/WFFjoi> Acesso em 17 de abril de 2015.

RDC 140. Resolução da Diretoria ColegiadaAgência nacional de vigilância sanitária. (2009). Disponível em < goo.gl/v7YPSl> Acesso em 17 de abril de 2015.

SPINILLO, C. G. Instruções visuais: algumas considerações e diretrizes para sequências pictóricas de procedimentos. Estudos em Design. Volume 9, n 3, Rio de Janeiro, 2001.

\section{; PADOVANI, S.; LANZONI, C.}

Ergonomia informacional em bulas de medicamentos e na tarefa de uso: um estudo sobre fármaco em suspensão oral. Revista Ação Ergonômica, v. 5, n. 1, 2011.

TWYMAN, M. L. Using pictorial language: a discussion of the dimensions problem. Designing usable texts, p. 245-312, 1985.

VOLPATO, L. F.; MARTINS, L. C.; MIALHE, F.L. Bulas de medicamentos e profissionais de saúde: ajudam ou complicam a compreensão dos usuários? Piracicaba: Revista de Ciências Farmacêuticas Básica e Aplicada, 2010, ISSN $1808-4532$

\section{Agradecimentos}

Agradeço a CAPES pelo apoio financeiro na concessão de bolsa e à minha orientadora, Dra. Carla Galvão Spinillo por todo apoio, orientação e dedicação para tornar possível está investigação. 